$11-1998$

Deterrence, Brutalization, and the Death Penalty: Another Examination of Oklahoma's Return to Capital Punishment

William C. Bailey

Cleveland State University, w.bailey@csuohio.edu

Follow this and additional works at: https://engagedscholarship.csuohio.edu/clsoc_crim_facpub

Part of the Criminology Commons, and the Law Enforcement and Corrections Commons

How does access to this work benefit you? Let us know!

\title{
Original Citation
}

Bailey, W. C. (1998). Deterrence, brutalization, and the death penalty: Another examination of Oklahoma's return to capital punishment. Criminology, 36(4), 711-734. doi:10.1111/j.1745-9125.1998.tb01263.x

\section{Repository Citation}

Bailey, William C., "Deterrence, Brutalization, and the Death Penalty: Another Examination of Oklahoma's Return to Capital Punishment" (1998). Sociology \& Criminology Faculty Publications. 38.

https://engagedscholarship.csuohio.edu/clsoc_crim_facpub/38

This Article is brought to you for free and open access by the Sociology \& Criminology Department at EngagedScholarship@CSU. It has been accepted for inclusion in Sociology \& Criminology Faculty Publications by an authorized administrator of EngagedScholarship@CSU. For more information, please contact library.es@csuohio.edu. 


\title{
DETERRENCE, BRUTALIZATION, AND THE DEATH PENALTY: ANOTHER EXAMINATION OF OKLAHOMA'S RETURN TO CAPITAL PUNISHMENT
}

\author{
WILLIAM C. BAILEY \\ Cleveland State University
}

$A$ replication and extension of a weekly ARIMA analysis (19891991) by Cochran et al. (1994), which appeared in Criminology, confirms that Oklahoma's return to capital punishment in 1990, after a 25 year moratorium, was followed by a significant increase in killings involving strangers. Moreover, a multivariate autoregressive analysis, which includes measures of the frequency of executions, the level of print media attention devoted to executions, and selected sociodemographic variables, produced results consistent with the brutalization hypothesis for total homicides, as well as a variety of different types of killing involving both strangers and nonstrangers. No prior study has shown such strong support for the capital punishment and brutalization argument. However, there is also a suggestion of a possible lagged deterrent effect for the level of media coverage of executions for nonfelony murders involving strangers. The analysis indicates that the impact of capital punishment in Oklahoma during the 1989-1991 period was much more extensive than suggested by the earlier study. Recommendations are made for further research examining additional jurisdictions and time periods to determine the generalizability of the patterns found for Oklahoma.

In an article that appeared in Criminology, Cochran et al. (1994) provide an important contribution to a long line of research examining the effect of capital punishment on murder. They point out that with few exceptions (Bowers and Pierce, 1980; Ehrlich, 1975, 1977; King, 1978; Phillips, 1980; Stack, 1987), death penalty investigators have found no consistent evidence that capital punishment is associated with either lower (deterrence) or higher (brutalization) homicide rates. Rather, the overwhelming pattern is support for the null hypothesis that capital punishment neither discourages nor encourages murder.

Despite this evidence, Cochran et al. argue that both deterrence and brutalization might be operating to some degree for different types of murder. However, because most researchers examine the overall homicide rate, this important variation is masked. That is, if capital punishment discourages some types of homicide but encourages other types, it is not 
surprising that most studies find essentially a "zero" relationship between capital punishment and the general homicide rate.

Deterrence investigators are not unaware of the need to examine deatheligible homicides. To the contrary, they long have recognized the importance of doing so, but have been hampered by the inability to disaggregate official homicide data. Several studies have overcome this obstacle and have examined some types of capital killings: premeditated murder and felony murder (Bailey, 1975, 1984; Dann, 1935; Peterson and Bailey, 1991; Savitz, 1958). Still, like general homicide studies, these efforts have provided no indication of deterrence.

Researchers examining the brutalization argument (Bowers, 1988; King, 1978) have not given systematic attention to which types of murder might be more or less encouraged by capital punishment. For example, Bowers and Pierce (1980:456) contend that executions devalue human life and legitimate lethal vengeance, but they do not indicate how brutalization operates for homicides occurring under different circumstances. In light of the limited understanding of whether brutalization/deterrence applies for different types of killing, the Cochran et al. article makes an important contribution by examining the influence of executions for different types of killing.

More specifically, Cochran et al. posit that killings involving strangers may be incited by capital punishment. They contend that, in general, if inhibitions against the use of lethal violence to solve problems created by "unworthy" others are reduced by executions, "such a brutalization effect is most likely to occur in 'situated transactions' . . . where inhibitions against the use of violence are already absent or considerably relaxed" (1994:110). Affronts by strangers involve such a context due to the fact that social ties, and hence social controls, are much weaker for persons not known to one another. Cochran et al. confirm empirically that for one jurisdiction, Oklahoma for 1989-1991, a return to capital punishment after a 25-year moratorium on executions was followed by an immediate and permanent increase in killings among strangers. A weekly time-series ARIMA analysis showed that the execution of Charles Troy Coleman on September 10,1990, was followed by a significant increase in overall stranger killings. However, not all types of homicide involving strangers increased significantly following the Coleman execution. Rather, significant increases were observed only for nonfelony and argument-related stranger killings. Felony-murders and robbery-related killings involving strangers did not increase significantly following the imposition of the death penalty on Coleman. Weekly killings neither increased nor decreased significantly for (1) total murders, (2) total felony murders, (3) total robbery-related killings, and (4) total death-eligible murders. Cochran et al. regard their findings as preliminary, and they call for further 
research "to explicate the links between the implementation of the death penalty and changes in the levels of both total and disaggregated measures of stranger homicides" (p. 130). This article provides further evidence on this important issue.

The analysis presented below extends the Cochran et al. study of Oklahoma homicides by (1) considering important death penalty variables not considered in the earlier analysis-the levels of execution and media coverage devoted to executions during the 1989-1991 period; (2) examining the immediate (within the week) and possible delayed deterrent/brutalization effects of the death penalty for the different types of murder; and (3) incorporating the execution and selected sociodemographic variables into a multivariate time-series regression analysis. This is done to avoid possible spurious results suggesting deterrent or brutalization effects for the Coleman intervention factor and the execution publicity variables that might be due to changes in demographic or economic conditions in Oklahoma during the period.

Cochran et al. have facilitated greatly this analysis by providing both the homicide file that they received from the Supplementary Homicide Reports (SHR) of the Oklahoma Uniform Crime Reports, and their weekly code sheets for different types of killing. With these two sources, I have been able to (1) replicate the Cochran et al. analysis for the types of homicide they examined, (2) extend their analysis by considering the impact of levels of execution and publicity for various types of stranger and nonstranger killings, and (3) examine the merits of ARIMA modeling versus multivariate autoregressive techniques for isolating the effect of capital punishment.

\section{METHODOLOGY}

Initially, I employed the same general methodology as Cochran and his colleagues. Using their code sheets and "raw" SHR homicide incident data, weekly time series were formed for the 1989-1991 period $(n=156$ weeks) for the types of murder examined earlier: (1) total killings, (2) total felony murders, (3) total robbery-related killings, (4) total death-eligible murders, (5) total killings involving strangers, (6) felony murders not involving strangers, (7) stranger robbery-related killings, (8) stranger nonfelony related murders, and (9) argument-related killings involving strangers. In addition, weekly time series were formed for (10) total nonstranger killings and (11) robbery-related killings not involving strangers. Cochran et al. did not consider these two related categories.

For the Cochran et al. analysis, the dependent variables were operationalized as the number of weekly homicide incidents. However, homicide 
victimization is the criterion variable typically used by death penalty investigators. Cochran et al. do not discuss why they chose to examine homicide incidents rather than victim counts. Initially, I viewed Cochran et al.'s choice to use homicide incidents, rather than victimizations, as the dependent variable as unfortunate because it would make it more difficult to compare their findings with those of previous death penalty analyses. Because some killings involve multiple victims, there are obviously more homicide victimizations than homicide incidents, but Cochran et al. do not discuss the ratio of the two.

Examination of the SHR data for Oklahoma for the 1989-1991 period shows that Cochran and his colleagues' decision to consider homicide incidents as the criterion variable does not pose a problem. Over the period, the data reveal a total of 690 homicide victims and 672 homicide incidents. That is, for the period most Oklahoma homicide incidents involved but a single victim (ratio: 690/672 = 1.07). Further, for the types of killings noted above, the correlation between weekly homicide incidents and victim counts ranges from .87 to 1.00 . Thus, the two time-series measure essentially the same thing. ${ }^{1}$ In light of this comparability, incident-based homicide measures are used in replicating and extending the Cochran et al. analysis. ${ }^{2}$

\section{THE COLEMAN EXECUTION: THE INTERVENTION VARIABLE}

Charles Troy Coleman was executed in Oklahoma on September 10, 1990. Cochran et al. treated the 88 weeks leading up to the execution as a pre-intervention period and the week of the execution through the end of December $1991(n=68)$ as an intervention period. However, because of the amount of publicity the week before the execution, they also considered an alternative variable that differentiated weeks $1-87$ from weeks

1. For the types of homicide considered, the respective correlations are as follows for the incident- and victim-based measures: total killings (.98); capital homicides (.93); total felony murders (.92); felony murders involving strangers (.91); felony murders not involving strangers (.97); total robbery-related killings (.87); robbery-related murders involving strangers (.90); robbery murders not involving strangers (.90); total killings involving strangers (.96); nonfelony murders involving strangers (.95); argument-related killings involving strangers (1.00), and total nonstranger killings (.98).

2. A reviewer of an earlier version of this article recommended using weekly offender counts, broken down by race of offender, as an additional dependent variable. The rationale provided for this recommendation was that whites and blacks may be differentially subject to deterrence, with blacks being less deterrable because they have a lower stake in conformity. Such an analysis was not conducted here due to the sizable proportion of homicide incidents in which (1) the number of homicide offenders involved is unknown or not reported by the Oklahoma authorities and (2) the race of the involved offender is unknown or not reported in the homicide data file. 
88-156. As one would predict, the results for the two intervention variables were the same because the $0 / 1$ coding for the pre- and intervention weeks only differs for one observation $(r=.987)$. Here, I rely on the former measure, treating the intervention period as beginning the week Coleman was put to death (week 89).

\section{EXECUTION PUBLICITY}

Cochran et al. view the Coleman execution as providing a natural quasiexperiment because of the considerable media attention that it received in Oklahoma. This may be the case, but it is important to note that the researchers did not examine the actual impact of media coverage of executions on weekly homicides. During the 1989-1991 period, citizens of Oklahoma were exposed not only to media coverage of the Coleman execution, which took place in their own state, but also to coverage of executions that took place in other jurisdictions. It is possible that media coverage in Oklahoma of executions that took place in other states could have a significant deterrent/brutalization effect for Oklahoma killings. If executions signal to citizens that it is right and proper to kill bad persons, the possible brutalization effect of capital punishment that results for Oklahoma citizens might not be restricted solely to executions that take place within the state of Oklahoma. Conversely, if executions signal to the public the negative consequences that can result from taking another person's life (deterrence), as well as validating the norm against killing (normative validation), the general preventive effects (Andenaes, 1974) of executions that take place in other jurisdictions might spill over to discourage killings in Oklahoma. I explore these possibilities in the analysis to follow.

Unfortunately, there is no systematic index, abstract, or other summary data available for Oklahoma's daily newspapers $(n=28)$, television stations $(n=26)$, or radio stations (over 200) that can be drawn upon to measure the amount of news coverage devoted to executions during the 1989-1991 period. This problem is not unique to Oklahoma; rather it has plagued other time-series analyses of execution publicity and state-level homicide patterns (King, 1978; Stack, 1990, 1993). A common practice has been to operationalize the amount of media attention devoted to executions as the level of coverage provided by the "newspaper of record" for a state, such as the South Carolina State for South Carolina (King, 1978) and The Atlanta Constitution for Georgia (Stack, 1993). Following this practice, I draw upon execution coverage that appeared in The Daily Oklahoman during the 1989-1991 period. The "Oklahoman" is the paper of record for the state, and has the largest circulation of the daily newspapers in Oklahoma.

During the three-year period there was a total of 53 executions in the 
United States. Of these, 33 received coverage in the Oklahoman, and coverage appeared during 30 of the 156 weeks in the time period. Drawing upon these data, a media variable was formed by summing the number of days of execution coverage per week (range, 0 to 5).

Linking execution coverage and homicides is somewhat problematic in a weekly time-series analysis. For example, the question arises whether levels should be tallied for the week that execution stories actually appear, or for a portion of the story week and the week to follow. To elaborate, if deterrence and/or brutalization is operative, it is reasonable to expect that an execution story that appears during the first few days of the week would be associated with a significant decline/increase in killings for that week. In contrast, the impact of media coverage of an execution that occurred during the last few days of the week (week $t$ ) might not be realized fully until the next $(t+1)$ week. The research reported below uses a measure of newspaper coverage of executions whereby stories that appeared during the first part of the week are considered as taking place during week $t$, and coverage that took place during the latter part of the week (during day 6 or 7 ) is considered as taking place during the next $(t+1)$ week. ${ }^{3}$

\section{OTHER EXECUTIONS}

As discussed above, 33 of the 53 executions that took place in the United States between 1989 and 1991 received one or more days of media coverage in the Oklahoman. The deterrence thesis predicts that, in general, homicides should be at a lower level for the weeks in which executions received coverage in the Oklahoman. The brutalization thesis predicts higher levels of killing for weeks with media coverage. However, it cannot be assumed that the 20 executions that did not receive coverage in the Oklahoman did not come to the attention of Oklahoma residents via alternative media sources, including other Oklahoma newspapers, outof-state papers, radio, television news, and the like. As noted, there are a number of other daily newspapers in the state, as well as television and radio stations. Thus, it is possible that a portion of Oklahoma residents learned of at least some of the 20 executions that did not receive coverage in the Oklahoman from other newspapers and electronic media, especially from neighboring states. Of note, during the 1989-1991 period executions took place in neighboring Texas $(n=13)$, Missouri $(n=6)$, and Arkansas $(n=2)$.

3. I also explored a media variable operationalized as the number of "story days" tallied according to the actual week of coverage, but the former variable was used here because it yielded more consistent results. 
Unfortunately, there is no way of knowing how many Oklahoma residents (1) learned from other media sources about the 33 executions that did receive coverage in the Oklahoman and (2) learned from other media sources about the 20 executions that were not covered by the state's paper of record. However, it is quite likely that some of the executions that did receive coverage in the Oklahoman also were carried by other sources, and that some of the executions that did not appear in the Oklahoman did receive attention by other media sources. For example, a spot check shows that one of the executions that did not receive coverage in the Oklahoman did receive coverage in the state's second largest daily newspaper-the Tulsa World, and another received coverage in a Dallas, Texas, daily newspaper that has considerable readership in southern Oklahoma.

In sum, the possibility cannot be ruled out that during the 1989-1991 period, at least some portions of the Oklahoma population were exposed to media coverage of executions from sources other than the Oklahoman. However, for all practical purposes, Oklahoma residents were not exposed to media coverage of executions for the weeks when no executions were conducted. Here, the only exception would be lingering coverage of an execution(s) that took place the previous week(s).

To take into consideration the fact that executions that did receive coverage in the Oklahoman also may have received coverage from other sources in the state, and that at least some of the executions that did not receive coverage in the Oklahoman did receive alternative media coverage in the state, I introduce the number of weekly executions as an additional death penalty variable in the multivariate analysis. The reasoning here is that the greater the number of weekly executions, the greater the probability of Oklahoma residents being exposed to media coverage of executions. I recognize that apart from weeks in which there were no executions, there was certainly not a one-to-one relationship between the number of weekly executions and the number of executions that were brought to the attention of Oklahoma citizens via the media. However, in the analysis to follow, it does not make sense to treat an execution-free week like a week with one or more executions simply because the execution(s) did not receive coverage in the Oklahoman.

During the 1989-1991 period weekly execution counts ranged from zero to three. As with the Oklahoman media coverage variable, a measure of the frequency of capital punishment is used whereby executions that took place during the first part of the week are considered as taking place during week $t$, and executions that took place during the latter part of the week (during day 6 or 7 ) are considered as taking place during the next $(t+1)$ week. 4

4. This measure is chosen over one that examines executions occurring during the 


\section{THE TIMING BETWEEN EXECUTIONS, EXECUTION PUBLICITY, AND HOMICIDES}

Time-series analyses of capital punishment have often considered the possibility that executions (and execution publicity) may have both immediate and lingering effects on homicides. For example, for a weekly timeseries analysis, the major deterrent/brutalization impact of the death penalty might be experienced during the execution week (week $t$ ), with effects diminishing during the weeks to follow (weeks $t+1, t+2 \ldots$ ). Or, it is possible that the major deterrent/brutalization impact of capital punishment is delayed by a week or two rather than immediate. A third possibility is that the deterrent effect of executions may be more immediate, while brutalization effects are delayed, or vice versa. To consider these possibilities, in the multivariate analyses that follow homicide counts for week $t$ are regressed against the execution frequency and the media variables for week $t, t-1, t-2$, and $t-3$ simultaneously. As the findings reported in the tables to follow make clear, both immediate and delayed execution effects are observed for some types of murder. Lagged execution variables for week $t-4$ and beyond were also explored, but without significant results.

\section{CONTROL VARIABLES}

To isolate the effect of the Coleman execution on homicides, Cochran et al. used ARIMA modeling to control for trend, drift, and autocorrelation. However, ARIMA modeling cannot (1) control specifically for third-variable sociodemographic factors known to be associated with homicide or (2) isolate the effect of multiple independent variables of interest, such as levels of execution and the amount of news coverage that executions receive. Rather, conventional ARIMA modeling generally is capable of assessing the impact of only a single intervention factor in a time series. Because the deterrence doctrine poses multiple dimensions of capital punishment as influencing offense behavior, and homicides are responsive to a number of important structural factors, only rarely (McFarland, 1983) have death penalty investigators used ARIMA techniques. 5 In this study,

actual execution week because it produces results that are more in line with theoretical expectations.

5. A reviewer of an earlier version of this article suggested that my concerns about the merits of ARIMA modeling for the Cochran et al. analysis are overstated because by whitening the data series for the different types of murder, Cochran et al. were able to control for the influence of executions, media coverage of executions, and sociodemographic factors. I disagree with the reviewer. First, by employing conventional ARIMA strategies, it is possible to more or less "whiten" a series such as the Oklahoma homicide data. When successful, various trend and noise factors are "controlled," but whitening is often somewhat problematic. Of greater concern, theoretically important noise factors were whitened in the Cochran et al. ARIMA analysis, 
I conduct a multivariate time-series analysis of Oklahoma homicides. By doing so, I can examine the influence of a variety of capital punishment factors, including the Coleman execution, and assess how well the modeling strategy used by Cochran et al. addresses brutalization/deterrence hypotheses.

Common structural control variables used in previous death penalty studies include (1) population size, (2) percent urban population, (3) percent population 15-34 years of age, (4) percent black population, (5) percent poverty, low income, or families on public assistance, and (6) the unemployment rate. During the relatively short period involved (1989-1991), Oklahoma did not change dramatically with respect to percents urban and black population. However, for the remaining variables there was sufficient change to possibly affect homicides. Thus, this analysis includes the following control factors: (1) population size (range $=$ 3.146 to 3.208 million), (2) percent population 15-34 years of age (range, $30 \%$ to $33 \%$ ), (3) percent population receiving AFDC benefits (range, $3 \%$ to $4 \%$ ), and (4) percent unemployment (range, $5 \%$ to $7 \%$ ). 6

As additional controls, monthly dummy variables for each type of homicide were included if the number of such killings was significantly higher

including levels of execution and the media coverage they received. But why treat executions and execution publicity as simply noise to be removed from the data series?

Levels of execution and the amount of publicity they receive (along with the Coleman intervention) are of fundamental theoretical importance to deterrence and brutalization arguments. For this reason, I view conventional multivariate autoregressive procedures as far more informative than standard single intervention ARIMA modeling in considering deterrence/brutalization questions for Oklahoma. Why be satisfied with a single Coleman execution intervention estimate with ARIMA when conventional multivariate autoregressive procedures also (1) provide an estimate for the effect of the Coleman intervention, (2) provide estimates for the impact of executions and execution publicity, as well as (3) provide estimates for how changing sociodemographic conditions over the 1989-1991 period may have influenced Oklahoma killings. The fundamental weakness of conventional ARIMA modeling for this type of study clearly is demonstrated by my findings for the frequency of executions and execution publicity variables.

6. Unfortunately, weekly figures were not available for the control variables for the 1989-1991 period. Rather, only monthly figures were available for the unemployment rate and AFDC factors; and only annual data were available for population size and percent population 15-34 years of age. In the multivariate analyses (Tables 2-6), month figures are used for the control variables. For the two population variables, monthly estimates were formed through linear interpolation. I do not view the use of monthly (rather than weekly) values for the control variables as a serious problem since my interest is not in directly estimating the impact of these structural factors on homicides. Rather, the control variables are included in the analysis to take into account general shifts in important sociodemographic conditions over the 1989-1991 period. 
or lower for a given month compared to other months. ${ }^{7}$ This method of controlling for months in which levels of homicide are atypically higher or lower than average is preferable to the practice of forming 12 distinct dummy variables and including 11 of the 12 monthly dummies in a regression analysis. While some death penalty researchers have done so, this procedure is not followed here because it treats each monthly dummy variable as if it makes a unique contribution to homicides, a pattern that to my knowledge never has been observed. Further, such a procedure needlessly sacrifices degrees of freedom in the analysis.

\section{MULTICOLLINEARITY}

To explore possible collinearity problems for the variables of interest, a series of auxiliary regressions were conducted in which each death penalty factor was regressed against the control and other execution variables. When the number of weekly executions was regressed against the controls, the Coleman execution intervention dummy (0/1) variable, and the execution publicity variable, the resulting $R^{2}$ value was .39 . When the media coverage variable was treated as dependent, the resulting $R^{2}$ value was .40 . And, when the Coleman intervention variable was treated as the criterion variable, the $R^{2}$ value was .75 .

The size of the $R^{2}$ value (.75) for the Coleman intervention variable indicates that this factor is associated strongly with some of the other predictors: percent 15-34 years of age $(r=-.77)$, level of unemployment $(r$ $=.53)$ and percent AFDC population $(r=.83)$. Because of these associations, it is important to consider the impact of the Coleman execution in a multivariate context. It is easy to imagine how Oklahoma's homicide patterns may have shifted over the 1989-1991 period due to changes in sociodemographic conditions, and these shifts seem to correspond with the pre- and Coleman-execution periods. However, to assume that the Coleman execution caused changes in sociodemographic conditions in Oklahoma obviously is not reasonable.

In contrast, the auxiliary regression analysis does not signal obvious collinearity problems for the execution frequency $\left(R^{2}=.39\right)$ and execution publicity $\left(R^{2}=.40\right)$ variables. However, the number of executions per week and the number of days of newspaper coverage of executions per week are correlated at a moderate level $(r=.615)$ for the 1989-1991 time

7. For total killings, capital homicides, stranger nonfelony murders, and nonstranger killings, counts were not significantly higher or lower than average for any of the 12 months. For total felony murders, incident counts were significantly below average for November; homicide frequencies were significantly higher than average for January for felony murders not involving strangers, total robbery-related murders, and robbery murders not involving strangers. For total killings involving strangers, counts were significantly above the monthly average for September. 
series. The relationship between these two death penalty variables has been raised as a matter of concern by a reviewer of an earlier version of this article. There is, of course, an asymmetrical dependence between the frequency of executions and media coverage of executions. Without the occurrence of an execution, there can be no media coverage. However, not all of the 53 executions in the United States during the period received coverage by the Oklahoman $(33 / 53=62 \%)$. Because of the overlap between these two variables $(n=33)$, the reviewer recommended that I first estimate the multivariate models including both the frequency of executions and amount of media coverage and, second, exclude the frequency of execution variable from the analysis. I do so in the analysis to follow in examining the dependency between the two execution variables. Alternatively, the regression models also are estimated including the frequency of execution variables and excluding the media coverage variables.

\section{FINDINGS}

The first step in the analysis was to "enter and proof" the data for the different types of homicide. Since Cochran et al. provided their data code sheets, I had no difficulty replicating the univariate patterns reported in the earlier study. Because the earlier findings are confirmed, results of this analysis are not reported in tabular or graphic form.

\section{BIVARIATE RESULTS}

The second step was to compare the average number of weekly killings before and after the Coleman execution for the different types of murder. Table 1 reports the mean number of homicides for the pre- $(n=88)$ and Coleman-execution $(n=68)$ weeks for each type of murder for the 1989-1991 period. Of the 12 offense categories, average weekly homicides increased for (1) total killings, (2) felony murders involving strangers, (3) total robbery-related killings, (4) robbery-related killings involving strangers, (5) total stranger killings, (6) stranger argument-related killings, and (7) stranger nonfelony killings. The increases were significant for total stranger killings, stranger argument-related killings, and stranger nonfelony killings. These results are consistent with Cochran et al.'s report of a "brutalization" pattern for these three offense categories.

In contrast, the average number of weekly (1) capital homicides, (2) total felony murders, (3) nonstranger felony murders, (4) robbery-related murders not involving strangers, and (5) nonstranger killings declined following the Coleman execution. However, none of these decreases was statistically significant.

In short, as Cochran et al. found, the before-after analysis is suggestive of a brutalization effect for the Coleman execution for some, but not 
Table 1. Summary of Weekly Homicide Incidents for Oklahoma, by Type of Killing for Pre-Coleman and Coleman Execution Periods, 1989-1991

\begin{tabular}{|c|c|c|c|c|c|c|}
\hline \multirow[b]{2}{*}{ Type of Homicide } & \multirow{2}{*}{$\begin{array}{l}\text { Victim } \\
\text { Group* }\end{array}$} & \multicolumn{2}{|c|}{$\begin{array}{l}\text { Pre-Coleman } \\
\text { Execution } \\
\text { Period } \\
\end{array}$} & \multicolumn{2}{|c|}{$\begin{array}{c}\text { Coleman } \\
\text { Execution } \\
\text { Period }\end{array}$} & \multirow[b]{2}{*}{$t$ Values } \\
\hline & & $N$ & Mean & $N$ & Mean & \\
\hline All Killings & $\mathrm{T}$ & 370 & $\overline{4.20}$ & 302 & $\overline{4.44}$ & 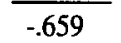 \\
\hline Capital Homicides & $\mathrm{T}$ & 48 & .55 & 34 & .50 & .363 \\
\hline Felony Murders & $\mathrm{T}$ & 64 & .73 & 44 & .65 & .602 \\
\hline Felony Murders & ST & 19 & .22 & 24 & .35 & -1.485 \\
\hline Felony Murders & NS & 30 & .34 & 15 & .22 & 1.342 \\
\hline $\begin{array}{l}\text { Robbery-Related } \\
\text { Killings }\end{array}$ & $\mathrm{T}$ & 29 & .33 & 30 & .44 & -1.071 \\
\hline $\begin{array}{l}\text { Robbery-Related } \\
\text { Killings }\end{array}$ & ST & 12 & .14 & 18 & .26 & -1.566 \\
\hline $\begin{array}{l}\text { Robbery-Related } \\
\text { Killings }\end{array}$ & NS & 17 & .19 & 12 & .18 & .229 \\
\hline Stranger Killings & ST & 37 & .42 & 53 & .78 & $-2.617^{* *}$ \\
\hline $\begin{array}{l}\text { Stranger Argument- } \\
\text { Related Killings }\end{array}$ & ST & 4 & .05 & 12 & .18 & $-2.351^{* *}$ \\
\hline $\begin{array}{l}\text { Stranger Nonfelony } \\
\text { Killings }\end{array}$ & ST & 18 & .20 & 29 & .43 & $-2.270^{* *}$ \\
\hline Nonstranger Killings & NS & 263 & 2.99 & 200 & 2.94 & .157 \\
\hline
\end{tabular}

other, types of stranger homicide. Of particular note, the brutalization effect of the Coleman execution appears to be confined to nonfelony, argument-related killings. The average number of felony murders (.22 vs. .35) involving strangers increased considerably following the Coleman execution, but not significantly (at the .05 level). There is no evidence of a significant deterrent effect resulting from the Coleman execution. The incident of felony murders not involving strangers (.34 vs. .22) declined noticeably, but not significantly, after this execution. The question of whether these bivariate patterns will continue to hold when additional execution and control factors are considered is addressed below.

\section{MULTIVARIATE ANALYSIS}

As a first step in the multivariate analysis, the autoregressive structure was examined for each type of murder for lag periods ranging through $t-20$ weeks. The SAS (statistical analysis system) autoregressive procedure (SAS Institute, 1985) was used to identify, and where necessary, to fit autoregressive models. In the regression analysis to follow, Yule-Walker estimates are reported where significant autocorrelation was observed. 
Ordinary least squares estimates are presented where there is not signifcant autocorrelation.

To reiterate, in general, the deterrence doctrine leads one to expect a significant inverse relationship between homicides and the Coleman intervention, levels of execution, and the amount of media coverage of executions, net of the control factors. Conversely, the brutalization argument predicts that death penalty factors should be associated positively with homicides when other variables are controlled. These predictions are considered in Tables 2-6. Table 2 reports the results for total killings, capital murders, homicides associated with other felonies, and robbery-related killings. ${ }^{8}$

Contrary to the deterrence perspective, there is no indication that the Coleman execution was followed by a significant decrease in weekly killings for any of the four homicide categories. Only for capital murders was there a noticeable decline in killings following the Coleman execution ( $b=$ -.348 , s.e. $=.225, t=-1.55$ ), but the reduction fell short of achieving statistical significance at the conventional .05 level $(t=1.66$ or higher). There also is no indication that levels of execution or the days of news coverage of executions in the United States produced a significant deterrent effect on homicides.

In contrast, there is a suggestion of brutalization in Table 2, but it stems from execution publicity rather than from the Coleman intervention or the number of executions. Neither of the latter two variables resulted in a significant increase in any of the four types of homicide. By contrast, for three of the four types of killing, one or another of the media variables is associated with a significant increase in homicides. The total number of Oklahoma killings increased significantly $(b=.751$, s.e. $=.367, t=2.05)$ during weeks $t$ when there was newspaper coverage of executions. In the case of capital homicides, the coefficient for media coverage of executions during week $t$ falls short of statistical significance ( $t=1.60 \mathrm{vs.} t=1.66)$, but the level of media attention given to executions for week $t-2$ is associated positively, and significantly, with these killings $(b=.230$, s.e. $=.129, t=$ 1.78). For robbery-related killings, the amount of media coverage of executions during the execution week is associated significantly, and positively, with this type of murder $(b=.185$, s.e. $=.108, t=1.71)$. None of the media variables is associated significantly with total felony murder.

In sum, Table 2 gives a clear suggestion that the overall level of murder, capital homicides, and robbery-related killings was encouraged, and not discouraged, in Oklahoma by media coverage of executions. I next

8. For reasons of parsimony, the results of the high/low monthly dummy variables are not reported in tabular form (Tables 2-6). 
Table 2. Summary of Regression Results for Total Homicides, Capital Homicides, Total Felony Murders, and Total Robbery-Related Killings

\begin{tabular}{|c|c|c|c|c|c|c|c|c|}
\hline \multirow[b]{2}{*}{ Predictor Variables } & \multicolumn{2}{|c|}{ All Killings } & \multicolumn{2}{|c|}{ Capital Homicides } & \multicolumn{2}{|c|}{$\begin{array}{c}\text { Total Felony } \\
\text { Murders }\end{array}$} & \multicolumn{2}{|c|}{$\begin{array}{l}\text { Total Robbery- } \\
\text { Related Killings }\end{array}$} \\
\hline & $b$ & S.E. & $b$ & S.E. & $b$ & S.E. & $b$ & S.E. \\
\hline Population & -.005 & .017 & -.010 & .006 & -.012 & .008 & -.009 & .006 \\
\hline$\%$ Age $15-34$ Years & .126 & .572 & .056 & .202 & .188 & .248 & .168 & .181 \\
\hline Unemployment Rate & -.167 & .299 & .181 & $.107^{*}$ & .063 & .139 & .101 & .119 \\
\hline$\%$ AFDC Population & 1.981 & 2.312 & .746 & .811 & 1.062 & .976 & .527 & .721 \\
\hline Coleman Intervention & -.231 & .633 & -.348 & .225 & -.178 & .281 & .152 & .205 \\
\hline \multicolumn{9}{|l|}{ No. of Executions } \\
\hline Week $t$ & -.267 & .385 & .116 & .134 & .065 & .149 & .065 & .113 \\
\hline Week $t-1$ & .055 & .389 & -.189 & .137 & -.124 & .156 & -.181 & .119 \\
\hline Week $t-2$ & .073 & .401 & -.064 & .141 & -.043 & .159 & -.106 & .122 \\
\hline Week $t-3$ & -.145 & .394 & -.021 & .137 & -.013 & .153 & -.088 & .117 \\
\hline \multicolumn{9}{|c|}{$\begin{array}{l}\text { No. of Days of } \\
\text { Newspaper Coverage }\end{array}$} \\
\hline Week $t$ & .751 & $.367^{*}$ & .205 & .128 & .205 & .143 & .185 & $.108^{*}$ \\
\hline Week $t-1$ & .215 & .364 & .172 & .127 & .123 & .144 & .135 & .109 \\
\hline Week $t-2$ & .274 & .369 & .230 & $.129 *$ & .139 & .145 & .143 & .109 \\
\hline Week $t-3$ & -.320 & .352 & -.004 & .122 & -.044 & .135 & .079 & .101 \\
\hline$R^{2}$ Value & .120 & & .161 & & .110 & & .109 & \\
\hline${ }^{*} p<.05$. & & & & & & & & \\
\hline
\end{tabular}

examine whether this apparent brutalization effect is a function of stranger killings that are included in these three offense categories.

\section{KILLINGS INVOLVING STRANGERS}

Table 3 reports the regression results for four categories of homicide involving parties not known to one another: (1) all killings involving strangers, (2) felony murders involving strangers, (3) nonfelony murders involving strangers, and (4) robbery-related killings involving strangers. 9 The results of this analysis are mixed for the deterrence and brutalization hypotheses. First, consistent with the results reported by Cochran et al., the Coleman execution was followed by a significant increase in overall stranger and nonfelony stranger killings, but not felony murder or robbery-homicide involving strangers. These more utilitarian types of stranger murder did increase following the Coleman execution, but not significantly.

Second, there is no indication that the volume of weekly or lagged executions caused a significant increase or decrease in the levels of total,

9. The offense category "argument-related killings involving strangers" $(n=16)$ is excluded from the multivariate analysis reported in Table 3 . Their very small number ( 4 during the pre-Coleman execution period and 12 following the Coleman execution) does not permit a reliable analysis. 


\section{Table 3. Summary of Regression Results for Homicides Involving Strangers}

\begin{tabular}{|c|c|c|c|c|c|c|c|c|}
\hline \multirow[b]{2}{*}{ Predictor Variables } & \multicolumn{2}{|c|}{$\begin{array}{l}\text { All Stranger } \\
\text { Killings }\end{array}$} & \multicolumn{2}{|c|}{$\begin{array}{l}\text { Stranger Felony } \\
\text { Murders }\end{array}$} & \multicolumn{2}{|c|}{$\begin{array}{l}\text { Stranger } \\
\text { Nonfelony } \\
\text { Killings }\end{array}$} & \multicolumn{2}{|c|}{$\begin{array}{c}\text { Stranger } \\
\text { Robbery-Related } \\
\text { Killings }\end{array}$} \\
\hline & $b$ & S.E. & $b$ & S.E. & $b$ & S.E. & $b$ & S.E. \\
\hline Population & -.009 & .008 & -.007 & .005 & -.002 & .006 & -.003 & .004 \\
\hline$\%$ Age 15-34 Years & .229 & .255 & .161 & .158 & .042 & .174 & .090 & .139 \\
\hline Unemployment Rate & -.036 & .145 & .005 & .088 & -.084 & .102 & .038 & .077 \\
\hline$\%$ AFDC Population & .652 & .991 & .671 & .630 & -.195 & .645 & .199 & .552 \\
\hline Coleman Intervention & .561 & $.317^{*}$ & .131 & .190 & .523 & $.220^{*}$ & .186 & .167 \\
\hline \multicolumn{9}{|l|}{ No. of Executions } \\
\hline Week $t$ & -.088 & .150 & -.032 & .094 & -.057 & .098 & -.001 & .087 \\
\hline Week $t-1$ & -.204 & .157 & -.224 & $.104^{*}$ & .005 & .103 & -.136 & .091 \\
\hline Week $t-2$ & -.031 & .160 & -.194 & $.106^{*}$ & .158 & .105 & -.106 & .093 \\
\hline Week $t-3$ & .041 & .152 & -.104 & .102 & .060 & .100 & -.016 & .089 \\
\hline \multicolumn{9}{|c|}{$\begin{array}{l}\text { No. of Days of } \\
\text { Newspaper Coverage }\end{array}$} \\
\hline Week $t$ & .263 & $.141^{*}$ & .110 & .094 & .174 & $.093^{*}$ & .130 & .082 \\
\hline Week $t-1$ & .004 & .143 & .172 & $.095^{*}$ & -.173 & $.094^{*}$ & .119 & .083 \\
\hline Week $t-2$ & .320 & $.145^{*}$ & .200 & $.096^{*}$ & .137 & .095 & .135 & .084 \\
\hline Week $t-3$ & .077 & .135 & .070 & .090 & .020 & .089 & -.015 & .079 \\
\hline$R^{2}$ Value & .166 & & .119 & & .177 & & .121 & \\
\hline
\end{tabular}

nonfelony, or robbery-related stranger murders. However, for felony murders involving strangers, the level of killing is associated negatively and significantly with the frequency of executions for week $t-1(b=-.224$, s.e. $=.104, t=-2.15)$ and week $t-2(b=-.194)$, s.e. $=.106, t=-1.83)$. Thus, there is an indication that the volume of executions may have had a delayed deterrent effect on stranger felony murder.

Turning to the media variables, total stranger killings were significantly higher $(b=.263$, s.e. $=.141, t=1.86)$ for weeks in which executions received coverage in the Oklahoman and for week $t-2$ coverage $(b=.320$, s.e. $=.145, t=2.21$ ). Similarly, for felony murders involving strangers, the positive media coefficients are significant for week $t-1(b=.172$, s.e. $=.095$, $t=1.81)$ and week $t-2(b=.200$, s.e. $=.096, t=2.08)$. However, for stranger nonfelony killings, there is a suggestion of brutalization for media coverage of executions during week $t$, but an apparent deterrent effect for levels of execution during week $t-1$.

In sum, there are suggestions of both brutalization and deterrence in Table 3. However, no simple explanation of the mixed pattern is possible. The same type of stranger murder (e.g., stranger felony and stranger nonfelony killings) appears to be encouraged by some aspects of capital punishment, but discouraged by others. For example, the number of executions seems to discourage stranger felony killings while media coverage appears to promote this type of homicide. Also puzzling, the media variables show conflicting patterns regarding nonfelony stranger murder. 
For reasons that are not obvious, there is a suggestion that the immediate effect (during week $t$ ) of media coverage of executions is to promote nonfelony stranger killings, but the impact turns in the opposite direction toward deterrence for the week $t-1$ media variable for these type of killings. Of interest, the positive week $t(b=.174)$ and negative week $t-1(b=$ $-.173)$ media coefficients are nearly identical in size and essentially cancel one another out for a net result of .001 .

\section{KILLINGS INVOLVING NONSTRANGERS}

Table 4 gives no indication of a significant deterrent effect for any of the death penalty variables for the three categories of homicide not involving strangers. The only suggestion of deterrence is for total nonstranger killings. On average, the weekly count for these types of killing declined by -.735 (s.e. $=.448, t=1.64$ ) following the Coleman execution, but this pattern falls just short of achieving statistical significance $(t=1.66)$.

Contrary to expectations and the Cochran et al. discussion, Table 4 suggests that the amount of media attention devoted to executions (but not the number of executions) actually may have promoted nonstranger homicides as well. The levels of total nonstranger homicide are associated significantly with the number of days of news coverage of executions during week $t-1(b=.517$, s.e. $=.293, \mathrm{t}=1.76)$. A similar pattern holds for nonstranger felony murders for the $t-3$ lagged media variable $(b=.144$, s.e. $=$ $.083, t=1.73$ ). It simply is unclear why a possible brutalization effect for newspaper coverage of executions might have been confined to the week $t-3$ (versus week $t, t-1$, or $t-2$ ) media factor for these type of killings.

\section{A FURTHER ANALYSIS}

A reviewer of an earlier version of this article questioned whether the dependence between the weekly frequency of executions and media coverage variables might pose a collinearity problem biasing the coefficients for the frequency of execution variables in a negative direction. Such a possibility could account for the mixed pattern observed for the two types of execution variables for felony murders involving strangers (Table 3).

To explore this dependency issue, each of the models presented in Tables 2-4 was reestimated excluding the frequency of execution variables for weeks $t$ through $t-3$. Following this procedure, the same pattern of findings resulted for the Coleman intervention and media coverage variables for all but four types of killing-capital homicides, total felony murders, nonfelony killings involving strangers, and robbery-related killings involving strangers. Because of the redundancy of the findings for the Coleman and media variables, I present in Table 5 the regression results 


\section{Table 4. Summary of Regression Results for Homicides Not Involving Strangers}

\begin{tabular}{|c|c|c|c|c|c|c|}
\hline \multirow[b]{2}{*}{ Predictor Variables } & \multicolumn{2}{|c|}{$\begin{array}{c}\text { Total Nonstranger } \\
\text { Homicides }\end{array}$} & \multicolumn{2}{|c|}{$\begin{array}{c}\text { Nonstranger Felony } \\
\text { Murders }\end{array}$} & \multicolumn{2}{|c|}{$\begin{array}{c}\text { Nonstranger } \\
\text { Robbery-Related } \\
\text { Killings }\end{array}$} \\
\hline & $b$ & S.E. & $b$ & S.E. & $b$ & S.E. \\
\hline Population & .005 & .013 & -.008 & .005 & -.006 & .004 \\
\hline$\%$ Age 15-34 Years & .026 & .434 & .179 & .145 & .137 & .123 \\
\hline Unemployment Rate & -.101 & .226 & .025 & .098 & .048 & .082 \\
\hline$\%$ AFDC Population & 1.754 & 1.791 & .921 & .577 & .670 & .478 \\
\hline Coleman Intervention & -.735 & .448 & -.188 & .160 & -.107 & .145 \\
\hline \multicolumn{7}{|l|}{ No. of Executions } \\
\hline Week $t$ & -.323 & .318 & -.054 & .094 & .035 & .079 \\
\hline Week $t-1$ & -.072 & .317 & -.008 & .098 & -.017 & .082 \\
\hline Week $t-2$ & -.408 & .325 & -.036 & .100 & .020 & .084 \\
\hline Week $t-3$ & -.065 & .326 & -.040 & .097 & -.058 & .082 \\
\hline \multicolumn{7}{|c|}{$\begin{array}{l}\text { No. of Days of } \\
\text { Newspaper Coverage }\end{array}$} \\
\hline Week $t$ & .414 & .298 & .131 & .087 & .043 & .074 \\
\hline Week $t-1$ & .517 & $.293^{*}$ & -.054 & .088 & -.048 & .074 \\
\hline Week $t-2$ & .209 & .295 & .021 & .090 & -.034 & .075 \\
\hline Week $t-3$ & -.311 & .284 & .144 & $.083^{*}$ & .107 & .069 \\
\hline$R^{2}$ Value & .118 & & .142 & & .143 & \\
\hline
\end{tabular}

only for the four offenses for which there were significant departures from the earlier (Tables 2-4) analyses.

The departures from the earlier pattern that are presented in Table 5 all provide additional evidence of a brutalization effect for publicized executions. For capital murders, again, there is a significant positive coefficient for week $t-2$ media coverage, but the positive media coefficient for week $t$ is now also significant $(b=.242$, s.e. $=.098, t=2.47$ ). Also in contrast to the earlier pattern, in the revised analysis the media coefficients for week $t$ are positive and statistically significant for both total felony murders $(b=$ .223 , s.e. $=.108, t=2.06)$ and robbery murders involving strangers $(b=$ .111 , s.e. $=.063, t=1.76$ ).

Also presented in Table 5 are the findings for nonfelony murders involving strangers. In the earlier analysis (Table 3 ), the media coefficient for week $t$ was positive and statistically significant $(b=.174$, s.e. $=.093, t=$ 1.87) and the coefficient for the media factor for week $t-1$ was negative and significant $(b=-.173$, s.e. $=.094, t=-1.84)$. The same mixed pattern holds in the extended analysis. Of note, however, the positive media coefficient for this type of killing now achieves statistical significance for week $t-2$ when the frequency of execution variables are excluded $(b=.240$, s.e. $=$ $.070, t=3.42$ ). 
Table 5. Summary of Regression Results for Selected Types of Homicide Excluding the Frequency of Executions as a Predictor Variable

\begin{tabular}{|c|c|c|c|c|c|c|c|c|}
\hline \multirow[b]{2}{*}{ Predictor Variables } & \multicolumn{2}{|c|}{$\begin{array}{c}\text { Capital } \\
\text { Homicides }\end{array}$} & \multicolumn{2}{|c|}{$\begin{array}{l}\text { Total Felony } \\
\text { Murders }\end{array}$} & \multicolumn{2}{|c|}{$\begin{array}{l}\text { Stranger } \\
\text { Nonfelony } \\
\text { Killings }\end{array}$} & \multicolumn{2}{|c|}{$\begin{array}{c}\text { Stranger } \\
\text { Robbery-Related } \\
\text { Killings } \\
\end{array}$} \\
\hline & $b$ & S.E. & $b$ & S.E. & $b$ & S.E. & $b$ & S.E. \\
\hline Population & -.009 & .006 & -.011 & .007 & -.003 & .006 & -.002 & .004 \\
\hline$\%$ Age $15-34$ Years & .004 & .184 & .150 & .228 & .097 & .167 & .021 & .128 \\
\hline Unemployment Rate & .180 & $.106^{*}$ & .061 & .138 & -.090 & .102 & .038 & .076 \\
\hline$\%$ AFDC Population & .539 & .724 & .909 & .879 & .025 & .607 & -.101 & .497 \\
\hline Coleman Intervention & -.345 & .223 & -.174 & .276 & .524 & $.220^{*}$ & .208 & .165 \\
\hline \multicolumn{9}{|c|}{$\begin{array}{l}\text { No. of Days of } \\
\text { Newspaper Coverage }\end{array}$} \\
\hline Week $t$ & .242 & $.098^{*}$ & .223 & $.108^{*}$ & .143 & $.070^{*}$ & .111 & $.063^{*}$ \\
\hline Week $t-1$ & .063 & .097 & .050 & .107 & -.149 & $.070^{*}$ & .033 & .063 \\
\hline Week $t-2$ & .187 & $.097^{*}$ & .108 & .106 & .240 & $.070^{*}$ & .073 & .063 \\
\hline Week $t-3$ & -.004 & .098 & -.045 & .107 & .049 & .070 & -.017 & .063 \\
\hline$R^{2}$ Value & .141 & & .103 & & .153 & & .102 & \\
\hline$p<.05$. & & & & & & & & \\
\hline
\end{tabular}

To explore further the possible dependency between the execution frequency and media coverage factors, I repeated the above analysis (Tables $2-4$ ), but now excluding the media variables. Table 6 reports the findings for this analysis for the five offense categories for which there was a significant change in the results for one or more of the weekly execution count variables.

Like the results reported in Table 5 , this extended analysis produces additional evidence of brutalization. Now, the level of executions for week $t$ is associated with a significantly higher number of capital homicides $(b=.266$, s.e. $=.105, t=2.53)$ and total robbery-related killings $(b=.156$, s.e. $=.089, t=1.75)$. In addition, week $t-1$ executions are associated with a significantly higher number of total killings $(b=.443$, s.e. $=.267, t=1.67)$, as are week $\mathrm{t}-2$ executions with felony murders not involving strangers $(b$ $=.271$, s.e. $=.074, t=3.66$ ).

Not only does excluding the media variables add to the evidence of brutalization for the execution frequency variables for these four types of murder, but the suggestion of a significant deterrent effect for executions for felony murders involving strangers is absent from Table 6 . In the earlier analysis (Table 3 ), the media coefficients were negative and statistically significant for week $t-1(b=-.244)$, s.e. $=.104)$ and week $t-2(b=-.194$, s.e. $=.106)$, but this is now no longer the case: $b=.071$, s.e. $=.079$ and $b=$ -.011 , s.e. $=.079$, respectively. These contrasting patterns suggest a dependence between the frequency of execution and media coverage variables that, at least for one offense category, artifactually produces an indication. of a deterrent effect for executions. 


\section{Table 6. Summary of Regression Results for Selected Types of Homicide Excluding the Newspaper Coverage of Executions As a Predictor Variable}

\begin{tabular}{|c|c|c|c|c|c|c|c|c|c|c|}
\hline \multirow[b]{2}{*}{ Predictor Variables } & \multicolumn{2}{|c|}{ All Killings } & \multicolumn{2}{|c|}{$\begin{array}{c}\text { Capital } \\
\text { Homicides }\end{array}$} & \multicolumn{2}{|c|}{$\begin{array}{l}\text { Stranger } \\
\text { Felony } \\
\text { Murders }\end{array}$} & \multicolumn{2}{|c|}{$\begin{array}{c}\text { Stranger } \\
\text { Nonfelony } \\
\text { Killings }\end{array}$} & \multicolumn{2}{|c|}{$\begin{array}{c}\text { Total } \\
\text { Robbery- } \\
\text { Related } \\
\text { Killings }\end{array}$} \\
\hline & $b$ & S.E. & $b$ & S.E. & $b$ & S.E. & $b$ & S.E. & $b$ & S.E. \\
\hline Population & -.007 & .017 & -.007 & .006 & -.004 & .005 & .001 & .005 & -.004 & .005 \\
\hline$\%$ Age $15-34$ Years & -.029 & .541 & -.129 & .187 & .014 & .150 & -.035 & .152 & -.010 & .165 \\
\hline Unemployment Rate & -.053 & .289 & .155 & .106 & -.014 & .088 & -.087 & .095 & .024 & .106 \\
\hline$\%$ AFDC Population & 1.481 & 2.169 & .071 & .768 & .151 & .607 & -.458 & .589 & -.082 & .695 \\
\hline Coleman Intervention & -.370 & .637 & -.362 & .224 & .103 & 192 & .494 & $.191^{*}$ & .145 & .188 \\
\hline \multicolumn{11}{|l|}{ No. of Executions } \\
\hline Week $t$ & .137 & .275 & .266 & $.105^{*}$ & .051 & .079 & .052 & .074 & .156 & $.089^{*}$ \\
\hline Week $t-1$ & .443 & $.267^{*}$ & -.014 & .103 & -.071 & .079 & -.033 & .074 & -.016 & .089 \\
\hline Week $t-2$ & .351 & .269 & .151 & .104 & -.011 & .079 & .271 & $.074^{*}$ & .015 & .089 \\
\hline Week $t-3$ & -.223 & .276 & .035 & .107 & .000 & .078 & .080 & .075 & .061 & .090 \\
\hline$R^{2}$ Value & .084 & & .125 & & .071 & & .145 & & .088 & \\
\hline
\end{tabular}

${ }^{*} p<.05$.

\section{SUMMARY AND CONCLUSIONS}

Increasingly some opponents of the death penalty contend that capital punishment has a brutalization rather than deterrent influence on homicide. In developing their arguments, these analysts seldom distinguish between types of homicide. The assumption appears to be that all types of killing are encouraged by capital punishment. By contrast, the deterrence doctrine emphasizes that the death penalty may be more effective in preventing some types of killings than others; still, few deterrence investigators have examined empirically homicides disaggregated by type. Rather, both deterrence and brutalization analysts tend to examine overall rates of homicide rather than specific types of killing.

The study by Cochran et al. (1994) is an important exception. They provide a rationale for why some types of murder may be deterred, while other types are incited, by executions. However, Cochran et al. did not take into consideration the deterrence/brutalization importance of multiple dimensions of capital punishment in their attempt to isolate the effect of Oklahoma's return to capital punishment. Importantly, Cochran et al. regard their work as preliminary and they encourage criminologists to replicate and extend their study. In this study, I have done so by employing a multivariate autoregressive analysis that incorporates additional death penalty factors and control variables that might have had an impact on Oklahoma killings.

Based on Cochran et al.'s arguments, I expected a brutalization effect 
for the frequency of execution and media variables for stranger, and especially nonutilitarian stranger, killings, but not for the other types of homicide. This expectation was not borne out by the analysis. First, after taking into consideration the sociodemographic control variables, the execution frequency, and media coverage factors, the evidence persisted that the Coleman execution was followed by a significant increase in total stranger killings and stranger homicides not involving other felonies. These findings parallel the results of the Cochran et al. ARIMA analysis.

Second, additional evidence of brutalization was observed from the initial (Tables 2-4) and extended (Tables 5-6) analysis for the execution frequency and media coverage variables for (1) total killings, (2) capital homicides, (3) total felony murder, (4) total robbery-related killings, (5) total stranger killings, (6) stranger felony murders, (7) stranger nonfelony killings, (8) stranger robbery-related killings, (9) total nonstranger homicides, and (10) nonstranger felony murders. For each of these offense categories, week $t$ or lagged execution counts and/or media coverage of executions was associated with a significant increase in weekly homicides. These findings suggest that executions that occurred in other states may have had a brutalization consequence in Oklahoma. Recall that between 1989 and 1991 only 1 of the nation's 53 executions took place in Oklahoma.

Third, the findings regarding the deterrence hypothesis are generally in line with previous studies. Of the 11 offense categories considered, there is no indication that media coverage of executions discourages homicide. There is one slight exception to this null pattern for stranger nonfelony killings for the week $t-2$ lagged media variable $(b=-.173, p<.05)$. This pattern persists when the frequency of execution variables are excluded from the analysis $(b=-.149$, s.e. $=.070, t=-2.13)$. I have no explanation for this quirky result. However, it is noteworthy that for the same offense for the initial analysis (Table 3), the significant coefficient for the week $t$ media factor $(b=.174, p<.05)$ is almost identical in size, but opposite in direction. When the week $t$ (brutalization) and week $t-1$ (deterrence) effects of media coverage are summed, the net result is essentially a zero media effect for stranger nonfelony killings. The pattern is quite similar for the media variables for week $t(b=.143)$ and week $t-1(b=-.149)$ in the extended analysis in which the frequency of execution variables are excluded from the models (Table 5). Of further interest, in this extended analysis the media coefficient for week $t-2$ is positive and statistically significant $(b=.240$, s.e. $=.070, t=3.43)$.

The only suggestion of a possible deterrent effect for capital punishment is for the frequency of execution variables for felony murders involving strangers. The initial analysis (Table 3 ) showed that higher levels of execution during week $t-1$ and week $t-2$ were associated with a significantly 
lower number of stranger felony murders $(b=-.224$ and $b=-.194$, respectively). However, even for these types of killing, definitive conclusions cannot be drawn. Recall (see Table 3 ) that the results for the week $t-1$ and week $t-2$ media variables were also significant for felony murders involving strangers, but in the opposite direction, thus suggesting a brutalization effect. These contrasting patterns are puzzling. Why would a higher number of executions discourage (deter) felony murders involving strangers, while higher levels of media coverage of executions promote (brutalization) these types of murder? The extended analysis presented in Table 6 may provide an answer to this question. As detailed above, when the execution media variables are excluded from the analysis, there is only a weak negative, and chance only, relationship between stranger felony murders and the frequency of executions for weeks $t-1$ and $t-2$. This pattern questions the possibility of a genuine (and not just apparent) significant relationship between felony murders involving strangers in Oklahoma and the level of weekly executions in the United States during the 1989-1991 period.

Finally, it should be noted that the goodness of fit of the models presented in Tables 2-6 is rather poor. The multiple $R^{2}$ values range from .110 to .166 . To a certain degree the poor fit may be due to important structural factors not being included in the analysis. However, a more likely explanation is that weekly homicide time series are subject to considerable noise and are by their nature not very stable. As temporal units of analysis become longer (such as with months, quarters, or years), homicide trends become more stable, and multivariate analyses typically produce better fits. To illustrate, from a monthly time-series analysis of execution publicity and the overall homicide rate in Georgia (1950-1965, $n=192$ months), Stack (1993) reports an $R^{2}$ value of only .19 . When years rather than weeks or months are considered in time series, $R^{2}$ values are commonly in the .60 to .80 range.

In short, the relatively low $R^{2}$ values associated with the above models are not a major concern. For this type of analysis, weeks are simply noise units. However, weeks are important units to consider if the deterrence/ brutalization effects of capital punishment are rather immediate and short lived.

In conclusion, this replication and extension of the Cochran et al. analysis demonstrates that it is a mistake for criminologists to treat the deterrence/brutalization question as a dead issue. It is equally a mistake for death penalty investigators to be content with "testing" deterrence/brutalization arguments by simply examining general homicides. Rather, detailed combinations of homicide circumstances and victim-offender relationships must be considered, as well as the possibility that the deterrent/ 
brutalization impact of capital punishment may differ for different dimensions of capital punishment.

I recommend that the next round of deterrence/brutalization research extend this analysis by considering additional and more diverse jurisdictions, and more extended time periods. Besides Oklahoma, a number of other states have returned to capital punishment in the past few years after long nonexecution periods (California, Illinois, Delaware, Washington, Wyoming). In addition, a number of jurisdictions that have not conducted an execution for decades have large death row populations (Ohio, Pennsylvania, Kentucky, Tennessee, New Jersey, Maryland). The former and latter jurisdictions (when executions resume) can be examined as additional natural quasi-experiments (Campbell, 1969) to both clarify and determine the generalizability of the findings for Oklahoma.

\section{REFERENCES}

Andenaes, Johannes

1974 Punishment and Deterrence. Ann Arbor: The University of Michigan Press.

Bailey, William C.

1975 Murder and capital punishment: Some further evidence. American Journal of Orthopsychiatry 45:669-688.

1984 Disaggregation in deterrence and death penalty research: The case of murder in Chicago. Journal of Criminal Law and Criminology 74:827-859.

Bowers, William J.

1988 The effect of executions is brutalization, not deterrence. In Kenneth C. Hass and James A. Inciardi (eds.), Capital Punishment: Legal and Social Science Approaches. Newbury Park, Calif: Sage.

Bowers, William J. and Glenn Pierce

1980 Deterrence or brutalization: What is the effect of executions? Crime and Delinquency 26:453-484.

Campbell, Donald T.

1969 Reforms as experiments. American Psychologist 24:409-429.

Cochran, John K., Mitchell B. Chamlin, and Mark Seth

1994 Deterrence or brutalization? An impact assessment of Oklahoma's return to capital punishment. Criminology 32:107-134.

Dann, Robert

1935 The Deterrent Effect of Capital Punishment. Philadelphia: The Committee of Philanthropic Labor of Philadelphia Yearly Meeting of Friends.

Ehrlich, Isaac

1975 The deterrent effect of capital punishment: A question of life and death. American Economic Review 65:397-417.

1977 Capital punishment and deterrence. Journal of Political Economy 85:741-788.

King, David R.

1978 The brutalization effect: Execution publicity and the incidence of homicide in South Carolina. Social Forces 57:683-687. 
McFarland, Sam G.

1983 Is capital punishment a short-term deterrent to homicide? A study of effects of four recent American executions. Journal of Criminal Law and Criminology 74:1014-1032.

Peterson, Ruth D. and William C. Bailey

1991 Felony murder and capital punishment: An examination of the deterrence question. Criminology 29:367-395.

Phillips, David D.

1980 The deterrent effect of capital punishment. Evidence on an old controversy. American Journal of Sociology 86:139-148.

SAS Institute Inc.

1985 SAS User's Guide: Statistics. Cary, N.C.: SAS Institute Inc.

Savitz, Leonard D.

1958 A study in capital punishment. Journal of Criminal Law, Criminology, and Police Science 49:338-341.

Stack, Steven

1987 Publicized executions and homicide, 1950-1980. American Sociological Review 52:532-540.

1990 Execution publicity and homicide in South Carolina: A research note. The Sociological Quarterly 31:599-611.

1993 Execution publicity and homicide in Georgia. Journal of Criminal Justice 18:25-39. 